\title{
GOLDMAN, Marcio. Mais alguma antropologia: ensaios de geografia do pensamento antropológico. São Paulo: Ponteio, 2016, 192p.

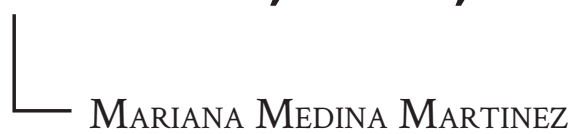 \\ Universidade Federal de São Carlos, São Carlos, São Paulo, Brasil
}

DOI 10.11606/issn.2316-9133.v25i25p455-461

Mais alguma antropologia (2016) é uma coletânea de seis textos escritos, em sua maioria, após a publicação de Alguma antropologia (1999) - a primeira reunião de artigos sobre temas que ocuparam a trajetória de pesquisa de Marcio Goldman. Tanto em uma como em outra coletânea, o antropólogo não omite sua predileção pela obra de determinados autores, certamente os que despertaram nele algum interesse para imersão no pensamento antropológico. Na primeira coletânea (1999), Goldman reúne treze escritos que orbitam três núcleos temáticos, a partir dos quais foram suscitados questionamentos a respeito das determinações do objeto antropológico, das abordagens históricas da disciplina e dos limites do método comparativo para a antropologia das sociedades complexas.

Se no livro anterior Goldman sinaliza como o elemento histórico inclina-se perigosamente para engendramentos universais, na introdução da recente coletânea ele anuncia que evitará utilizar a história como um "dispositivo crítico" para compreender as condições de produção dos saberes. Como abordar criticamente o pensamento antropológico sem uma historicidade que conduza as linhas de questionamentos? Como escapar de uma perspectiva que não recaia nos limites da história, quando nela inevitavelmente se enraíza algum tipo de universalismo transcendental? Como recuperar o intempestivo ou o intemporal, os quais Deleuze (1968, p. 3) notou terem ocorrido raras vezes na antropologia? São essas algumas das questões polemizadas em sua introdução.

O autor anuncia, portanto, um caminho pelo qual a antropologia não historicizante poderia funcionar, apresentando, ainda que de maneira breve, a sua proposta de uma geografia do pensamento. Para montar retratos do ambiente antropológico, Goldman busca em Deleuze (1990) a recomendação de que cartografias não devem reproduzir pinturas fidedignas dos terrenos vasculhados, mas trataria de explicitar o que está presente naquele pensamento e que o próprio autor não diz. Nessa seleção, uma investigação cuidadosa mapeia o pensamento de autores expressivos como Godfrey Lienhardt, Claude Lévi-Strauss, Pierre Clastres, Jeanne Favret-Saada, Marylin Strathern e Roy Wagner. Seu in- 
tuito não é compreender as condições do que é dito e feito nessas obras (porque também aqui se encerram os limites dos determinismos históricos), mas, certamente, mapear como se pensam certas ideias.

A escolha desses autores, alguns bastante difundidos na academia brasileira de hoje, incita leitores e leitoras a repensar a relação com o passado e a notar os elementos que fizeram tais pensamentos serem celebrados ou deixados de lado. Lienhardt, por exemplo, é um dos que não foram assimilados nas narrativas majoritárias. Diferente dos africanistas da década de 1960, no lugar de verificar tipologias da organização social, seu questionamento o leva a buscar alternativas tanto para livrar-se dos riscos do utilitarismo totêmico quanto para explicar na religião dinka aquilo que não poderia ser facilmente comunicado em palavras.

A noção de experiência, central para a abordagem de Lienhardt em Divinity and Experience: the Religion of the Dinka (1961), o lança para além dos referenciais do estrutural-funcionalismo e das explicações puramente teológicas ou psicológicas da religião. Ao falar da experiência, ele se esquiva dos debates estéreis em torno da crença e do rito, assim como evita recair nas armadilhas impostas por explicações representacionais sobre as entidades. É por isso que a experiência religiosa não exprime de modo algum o que as divindades representam para os praticantes dinkas; ela manifesta um "estado afetivo do sofredor" (LIENHARDT, 1978 [1961], p. 148), supostamente inacessível ao antropólogo, mas externalizado através da evocação de experiências e paixões do indivíduo em seu grupo específico e da invocação de mitos cosmológicos, como sugere Goldman (2016, p. 26).

Disso resulta que a relação com os poderes divinos não se encerra na passividade do crente em relação aos deuses. Isso porque experiências religiosas são construídas por paixões convertidas em causas, que podem ser interpretadas como “o efeito de uma ação provinda de alhures” (GOLDMAN, 2016, p. 151). Essa manobra, surpreendente à época, levou Goldman a sugerir que tal noção permitiu a Lienhardt propor uma teoria etnográfica da religião: "uma chave que pode servir para conferir inteligibilidade a outras formações religiosas, em outros contextos sociais e culturais" (GOLDMAN, 2016, p. 31).

Com a mesma intenção de vasculhar terrenos de pensamento, o retrato que Goldman traça de Lévi-Strauss reconstrói a vastidão desse empreendimento estruturalista para a antropologia. Para montar a geografia desse pensamento, Goldman recuperou as três paixões do antropólogo francês. Com a geologia, Lévi-Strauss compreende que há um princípio ordenador para além da aleatoriedade das formações geológicas; no marxismo, a infraestrutura organizaria os demais fenômenos sociais; e, na psicanálise, os comportamentos individuais seriam derivados de uma racionalidade subjacente ao inconsciente. Essas paixões, segundo Goldman, expressam-se na intuição lévistraussiana em verificar algum sentido regulador diante da desordem aparente do mundo. Da linguística, pai- 
xão não declarada do autor, ele emprestara um método para dar ordenamento à complexidade de uma ciência do concreto interessada no mundo sensível.

Os mitos, analisados minuciosamente em sua tetralogia As mitológicas (1964; 1966; 1968; 1971), não por acaso teriam atraído a atenção do antropólogo. Aparentemente despidos de qualquer função prática e compostos por elementos caóticos, os mitos não deixam de apresentar uma lógica, uma unidade do pensamento revelada em constrangimentos imanentes ao próprio pensar. Apesar de Lévi-Strauss ter enfatizado que seu estruturalismo seria um método, a análise estrutural dos mitos manifesta uma filosofia, segundo a leitura de Goldman. Levando em conta tal constatação, Goldman aponta um caráter filosófico desse pensamento que torna possível situar a antropologia de Lévi-Strauss diante de grandes questões da humanidade.

O próximo autor convidado por Goldman para compor sua coletânea é Pierre Clastres. Depois de ter pesquisado religiões de matriz africana na Bahia, Goldman foi atraído pela política a partir de uma pesquisa de campo num terreiro de candomblé. Ao tentar apreender o processo eleitoral do ponto de vista do movimento negro de Ilhéus, Goldman entendeu que o modo como a política partidária dessa cidade incide sobre tal movimento revela uma perspectiva descrente sobre os procedimentos partidários ditos democráticos. De certo, o pensamento clastriano teria auxiliado Goldman a compreender que, ao contrário dos julgamentos que supõem serem alienados eleitores e eleitoras baianas, o autor identifica que a visão cética do movimento negro é "sem dúvida uma perspectiva contra o Estado” (2016, p. 94). É por isso que Clastres seria, para Goldman, um desses autores que aprimoram uma série de questionamentos e, por isso, iluminam um campo de visão inusitado.

A fórmula, aparentemente simples, "a sociedade contra o Estado" guardaria alguns aforismas preciosos, discutidos por Goldman nesse capítulo. Tais sentenças teriam dado ao etnólogo francês as condições para provocar um descentramento fundamental na antropologia: a recusa do ponto de vista do Estado para falar do poder e da política, de acordo com Goldman (2016, p. 98). A partir disso, Clastres teria entendido que o pensamento antropológico não havia abandonado sua grande fixação evolucionista, a convicção etnocentrista de que a história teria um sentido único e o Estado seria o destino de toda sociedade. Clastres teria sido um dos responsáveis, segundo Foucault (1976, p. 184), por fazer com que o pensamento político deixasse de orbitar em torno da noção moderna de Estado, ou seja, a noção de poder político como algo necessariamente centralizado e coercitivo.

O pensamento clastriano imprimiu, sem dúvida, alguma singularidade nos escritos do antropólogo brasileiro. Trabalhar com Clastres, como prefere Goldman, implica notar que há na perspectiva "contra o Estado" uma série de mecanismos dispersos em muitos processos micropolíticos, sejam eles ocidentais ou não. Daí 
verifica-se a excelência de sua obra e a capacidade de conectar essa ideia com materiais arqueológicos, epistemológicos e filosóficos (GOLDMAN, 2016, p. 102).

$\mathrm{O}$ quadro seguinte da coletânea traz a imagem do pensamento de Jeanne Fravret-Saada. Se a tradução brasileira de Etre affecte ${ }^{1}$ (1990) popularizou-se entre antropólogos e antropólogas por aqui, a disseminação e predileção dessa autora na academia brasileira nos anos 2000 não correspondeu a sua pouca aceitação em ambientes franceses. Na contramão de um tempo produtivista da academia, Favret-Saada passou demorados anos na região do Bocage e procurou esquivar-se dos procedimentos de investigação etnográficos mais usuais para compreender que o tempo é essencial para "ser afetada". Goldman, em acordo com a antropóloga, também defende que relações mais íntimas e complexas não são construídas às pressas, por isso, o tempo seria fundamental nas pesquisas de campo, configurando então uma relação (GOLDMAN, 2016, p. 112).

Ao aceitar que um movimento paciente e cuidadoso dita o ritmo da feitiçaria, Favret-Saada pôde vivenciar forças tão intensas, capazes de suscitar tantos afetos, que, enfim, acabou deixando-se enfeitiçar. É por isso que acreditar na feitiçaria ou experimentá-la não implica necessariamente identificar-se com o ponto de vista nativo, mas olhar com mais atenção para uma comunicação não intencional e involuntária. A compreensão dessa linguagem e sua aceitação em imprimi-la no texto etnográfico permitiram que Favret-Saada contornasse as explicações carregadas de racionalidade utilitária sobre o uso terapêutico desses rituais.

A inclinação da autora para forças que puderam movê-la para lugares menos regulados pelo produtivismo imperante, pelo cientificismo enrijecido e pela objetividade de diferentes programas de verdade, sem dúvida, acompanhou a originalidade de sua antropologia. Com isso, Favret-Saada nos revela que afetos como esses podem produzir "um modo não partidário de ser em política e um modo não escolar de fazer a pesquisa” (FAVRET-SAADA, 1984).

O conjunto de obras de Marylin Strathern também exige uma leitura em compassos lentos para uma apreensão justa da extensão e profundidade de uma antropologia feita em câmera lenta, como sugere Goldman, em parceria com Viveiros de Castro nesse capítulo (GOLDMAN, 2016, p. 119-127). Nos textos "O efeito etnográfico" (I e II) (STRATHERN, 1999a; 1999b), a autora informa que uma descrição de fato relacional deve dar lugar a uma experimentação de troca de perspectivas no próprio texto. Esse tipo de escrita não recupera o projeto etnográfico pós-moderno, já que não se trata de dissociar pontos de vistas porque eles estariam embaralhados na escrita. Diferente disso, os discursos da antropóloga e dos melanésios aparecem separados em texto porque tanto uns como outros servem como materiais analíticos acerca do modo como são produzidas as explicações e os diferentes pontos de vista, tanto lá quanto aqui.

${ }^{1}$ FAVRET-SAADA, Jeanne. Ser afetado. Cadernos de campo, n. 13, 2005. 
Uma leitura lenta e pausada do texto "Nem partes, nem todos" (STRATHERN, 1992), tal como recomendam Viveiros de Castro e Goldman nesse capítulo (GOLDMAN, 2016, p. 133), é indispensável para compreender que a antropóloga inglesa indica uma abordagem múltipla, ou, ainda, uma escolha pela multiplicidade como alternativa aos dualismos conceituais. Seguindo com essa abordagem, Goldman e Viveiros de Castro entendem que oposições dicotômicas (sujeito/objeto, nós/eles, eu/outro etc.), que tanto perseguiram a construção do pensamento antropológico, não deveriam ser compreendidas como unidades essencializadas, mesmo que não sejam colocadas em relação dicotômica, pois os autores apontam que todos os termos das relações seriam em si multiplicidades.

No mapeamento das ideias de M. Strathern, Goldman (2016) também traz à tona os limites de uma antropologia em casa e de uma autoantropologia. Dessa forma, o autor resgata a crítica de Strathern (1996) aos procedimentos etnográficos de Latour (1994). Este último procurou encontrar nos híbridos a chave para recompor a multiplicidade do ser moderno, recorrendo às redes sociotécnicas como metodologia para conciliar distinções ontológicas. Strathern, entretanto, lembra que a pergunta elementar e também tradicional na etnografia não deve ser abandonada: não se trata de saber o que é uma rede na Melanésia, mas de "o que seria uma rede para os melanésios?". Sem esse questionamento, não é possível produzir efeitos etnográficos nem lá nem aqui, ou entre nós e os outros.

O último texto da coletânea é uma resenha da tradução brasileira de $A$ invenção da Cultura (WAGNER, 2010 [1975]), intitulada "O fim da antropologia" (GOLDMAN, 2011). Traduzido pouco mais de três décadas depois de sua publicação, o caráter inovador de Wagner nos anos 1970 soou algo descolado das saídas interpretativas e culturalistas da época. Mas se essas duas últimas abordagens remetem ao fim de uma antropologia do século XX, Wagner anuncia que uma das saídas para os limites da cultura estaria nos mecanismos internos da etnografia.

Para incorporar uma autorreflexão antropológica, Wagner defende que é preciso tornar evidentes os procedimentos que sustentam e determinam a cultura em que o antropólogo vive, já que seríamos prisioneiros inconscientes de nossos regimes culturais. A escrita, portanto, seria a ferramenta mais potente para tornar evidentes os procedimentos conceituais que os analistas mobilizam (seja por metáforas, reificações, objetificações, generalizações etc.) para pensar o que seria a cultura em qualquer contexto. Com isso, Wagner defende que a escrita etnográfica é capaz de desenvolver poderosos e decisivos cânones de reflexão, em geral relegados à teoria. Disso recuperamos a centralidade da ideia de invenção: inventar culturas não é torná-las ficcionais, mas criá-las nos textos.

Com esse tipo de crítica feita por dentro da própria escrita etnográfica, Wagner introduziu, ainda que de maneira precoce para seu tempo, um vitalismo antropológico, segundo Goldman. Essa afirmação pode ser entendida como um movimento feito por Wagner para compreender como os antropólogos tor- 
nam inteligíveis o que vivenciam e observam. É por isso que Goldman entende que Wagner teria esboçado uma antropologia da vida, não da evolução, mas da história, da cognição, da estrutura ou da função.

Mais alguma antropologia (2016) renova, portanto, o olhar sobre os autores com os quais Goldman dialoga. Esse ensaio da geografia do pensamento antropológico estabelece conexões com terrenos que não exatamente se sedimentaram em algum lugar do passado. Talvez seja por outra razão que Goldman nos faz lembrarmo-nos dessas imagens clássicas do pensamento, muito provavelmente porque enxerga neles a possibilidade de pensar a nossa atualidade através do diferencial. A distinção entre os pensadores abordados nessa coletânea possivelmente não esteja na comoção que esses personagens tenham provocado em nós por alguma essência imutável das ideias, mas pela capacidade desses pensamentos de serem reatualizados ao passar do tempo.

\section{Referências bibliográficas}

DELEUZE, Gilles. Différence et répetition. Paris: PUF, 1968.

Sur la philosophie. In: Pourparles. Paris: Minuit, 1990.

FAVRET-SAADA, Jeanne. Jeanne Favret-Saada. In : Idées contemporaines. Entretiens Le Monde. Paris: La Découverte: 1984.

. Être Affecté. In: Gradhiva: Revue d'Histoire et d'Archives de l'Anthropologie, n. 8, 1990, p. 3-9.

FOUCAULT, Michel. Les Mailles du pouvoir. In: Dits et écrits. v. IV. Paris: Gallimard, 1994 [1976]. p. 182-201.

GOLDMAN, Marcio. Alguma antropologia. Rio de Janeiro: Editora Relume Dumará, 1999.

. O fim da antropologia. In: Novos Estudos Cebrap, São Paulo, n. 89, mar. 2011.

LATOUR, Bruno. Jamais fomos modernos. Rio de Janeiro: Editora 34, 1994.

LÉVI-STRAUSS, Claude. Mythologiques I: le cru et le cuit. Paris: Plon, 1964.

. Mythologiques II: du miel aux cendres. Paris: Plon, 1966.

Mythologiques III: l'origine des manières de table. Paris: Plon, 1968.

. Mythologiques IV: l'homme nu. Paris: Plon, 1971.

LIENHARDT, Godfrey. Divinity and Experience: the religion of the Dinka. Oxford: The Clarendon Press, 1978 [1961].

STRATHERN, Marylin. Cutting the Network. The Journal of the Royal Anthropological Institute, v. 2, n. 3, set. 1996, p. 517-35.

The Ethnographic Effect I. In: Property, Substance and Effect. Anthropo-

logical essays on persons and things. Londres: Athlone Press, 1999a. p. 1-26.

The Ethnographic Effect II. Writing societies, writing persons. In: 
Property, Substance and Effect. Anthropological essays on persons and things. Londres: Athlone Press, 1999b. p. 229-61.

WAGNER, Roy. A invenção da cultura. São Paulo: Cosac Naify, 2010 [1975].

\section{autora Mariana Medina Martinez}

Doutora em Antropologia Social pela Universidade Federal de São Carlos.

Recebido em 01/12/2017 Aceito para publicação em 13/02/2017 